\title{
Produtividade de Plantas de Pinhão Manso Cultivadas em Diferentes Espaçamentos
}

\author{
Marcus V. P. Cassiano, Luis F. O. Borges, Alainy C. S. Nascente, \\ Pollykennya K. F. Alves, Victor P. Godoi, Larissa P. Borges, Mariana \\ S. Carmo \& Fábio S. Matos
}

O presente estudo teve como objetivo avaliar a produtividade de plantas de pinhão manso cultivadas em diferentes espaçamentos. O trabalho foi conduzido no campo experimental da Universidade Estadual de Goiás em Latossolo Vermelho-Amarelo. Utilizou-se o delineamento experimental em blocos casualizados com três tratamentos (plantas cultivadas nos espaçamentos $3 \times 1,3 \times 2$ e $3 \times 3$ m) e seis repetições. A competição entre plantas de pinhão manso pouco afetou o crescimento vegetativo das plantas, no entanto, com o desenvolvimento dos frutos, drenos que mais demandam assimilados na planta, a competição por recursos abióticos contribuiu para redução da produtividade.

Palavras-chave: Densidade de plantas; Jatropha curcas; rendimento de sementes.

The present study aimed to evaluate the productivity of Jatropha curcas plants grown at different spacings. The work was conducted in the experimental field of the University of Goiás in Oxisol. We used a randomized complete block design with three treatments (plants grown in spacing $3 \times 1,3 \times 2$ and $3 \times 3 \mathrm{~m}$ ) and six replications. Competition between plants of Jatropha curcas had little effect on the vegetative growth, however, with the development of the fruit, drains demand more assimilated in the plant, the competition for abiotic resources in plants densest contributed to reduced productivity.

Keywords: Plant density; Jatropha curcas; seed yield. 


\section{Introdução}

$\mathrm{O}$ incremento dos níveis dos gases de efeito estufa, notadamente dióxido de carbono $(\mathrm{CO} 2)$ na atmosfera terrestre, tem intensificado a busca por combustíveis renováveis, tipo biodiesel, visando reduzir o consumo de combustíveis fósseis. A busca por uma alternativa energética aos combustíveis fósseis requer a avaliação de fontes renováveis e de baixo impacto sobre o ambiente natural. São primazes o desenvolvimento de tecnologias apropriadas e a definição da matéria-prima a ser utilizada para a geração de energia, sem ou com o mínimo de prejuízos ao ambiente.

O Brasil apresenta grande potencial para produção de biocombustíveis em grande parte de sua extensão territorial, em função de suas características edafoclimáticas, biodiversidade (várias espécies potenciais para produção de biocombustíveis adaptadas a diferentes climas e biomas), disponibilidade de área e de mão-de-obra, bem como comprovada competência técnica no campo da ciência agrícola ${ }^{1,2}$. Além disso, as exigências para cultivo de plantas são perfeitamente atendidas pelas condições brasileiras, pois o país possui água e luz solar em abundância. Por último, argumentase que o Brasil tem grande oferta de mão-de-obra para alavancar a produção no campo; riqueza de espécies vegetais das quais se podem extrair bioetanol, biodiesel e bioquerosene, e tradição em geração de energia limpa. Todas essas condições reunidas já colocam o Brasil na liderança da produção mundial de agroenergia, notadamente de agrocombustíveis. O Programa Nacional de Produção e Uso do Biodiesel (PNPB) brasileiro fomenta a produção de oleaginosas para suprir às indústrias com matéria-prima, adotando o enfoque no desenvolvimento regional e da inclusão social por meio do "Selo Combustível Social" do Ministério do Desenvolvimento Agrário (MDA).

As principais matérias-primas utilizadas para produção do biodiesel no Brasil são soja, sebo bovino e algodão, com contribuições de 71,13\%, 18,66 \% e 4,69\%, respectivamente, sendo os outros materiais responsáveis por apenas 4,08 \% da produção ${ }^{3}$. Existe a necessidade, portanto, de diversificar a produção de matéria-prima para produção de biodiesel, por meio da introdução de espécies promissoras, como Jatropha curcas L.
J. curcas (Euphorbiaceae) é uma espécie oleaginosa, conhecida popularmente como pinhão manso. É originário da América Central, mais especificamente no México. Os índios que migraram da América do Norte para a América do Sul, há mais de dez mil anos, seriam os responsáveis por sua distribuição do México até a Argentina, incluindo o Brasil ${ }^{4,5}$. A espécie possui grande potencial econômico, sobretudo, por suas sementes constituírem matéria-prima para a produção de óleo para biodiesel. Esta característica tem contribuído para o aumento da exploração comercial dessa cultura. O pinhão manso é considerado planta rústica e adaptada às mais diversas condições edafoclimáticas, desenvolve-se bem em solos marginais de baixa fertilidade. Trata-se de um arbusto de desenvolvimento rápido, podendo iniciar sua produção já no sétimo mês após o plantio, permanecendo produtiva por aproximadamente 40 anos 4 .

Atualmente, há duas grandes preocupações quanto ao cultivo do pinhão manso: primeiro, existem poucas informações sobre os aspectos agronômicos básicos da cultura como recomendação de adubação, densidade de plantas e maturação desuniforme de frutos e segundo, trata-se de uma espécie silvestre com nenhum grau de melhoramento ${ }^{6}$. O pinhão manso ainda é considerado uma planta silvestre ${ }^{7,8}$, com poucas informações disponíveis a respeito da performance das sementes ou acessos. Com o desenvolvimento de novas pesquisas, espera-se que a cultura deixe de ser potencial e passe a ser efetivamente uma matéria-prima para o mercado de biodiesel ${ }^{9,10}$.

Com a possibilidade do uso do óleo de pinhão manso para a produção de biodiesel, abrem-se amplas perspectivas para o aumento das áreas de plantio dessa cultura em diversas regiões. A densidade de plantas é variável decisiva na produtividade de plantas de quaisquer espécies. Apesar da planta de pinhão manso ser rústica e produtiva em solos de baixa fertilidade, espera-se obter maiores rendimentos em solos férteis e densidade populacional adequada para minimizar a competição e permitir exploração de maior volume de solo. A produtividade das espécies é dependente do potencial de extração de água e nutrientes e absorção de energia luminosa inerentes a cada espécie vegetal. $\mathrm{Na}$ escolha do espaçamento em campo, busca-se reduzir a competição entre as plantas fornecendo água e nutrientes na quantidade adequada. $\mathrm{O}$ adequado arranjo de plantas 
visa, entre outros aspectos. maximizar a incidência da radiação solar, uma vez que a redução na disponibilidade de energia luminosa tem sido apontada como causa do baixo rendimento das culturas em campo ${ }^{11}$.

As pesquisas com pinhão manso têm-se concentrado em estresse abiótico; melhoramento de plantas e aplicação de reguladores de crescimento, porém, a averiguação do adequado espaçamento tem sido pouco pesquisada e carece de elucidação científica. O presente estudo teve como objetivo avaliar a produtividade de plantas de pinhão manso, cultivadas em diferentes espaçamentos. Isso se deve à necessidade de buscar informações de tal natureza para obtenção de elevadas produtividades em campo, possibilitando exploração comercial.

\section{Material e Método}

O trabalho foi conduzido no campo experimental da Universidade Estadual de Goiás, unidade de Ipameri (Lat. 170 43' 19” S, Long. 480 09' 35” W, Alt. 773 m), Ipameri, Goiás. Esta região possui clima tropical com inverno seco e verão úmido (Aw), de acordo com a classificação de Köppen. Plantas de pinhão manso, com um ano de idade, foram cultivadas nos espaçamentos ( $3 \times 1 \mathrm{~m} ; 3 \times 2 \mathrm{~m}$ e $3 \times 3$ $\mathrm{m})$. O delineamento experimental utilizado foi em blocos casualizados com três tratamentos e seis repetições. O solo da área experimental é o Latossolo Vermelho-Amarelo. $\mathrm{O}$ pH dele foi corrigido e a adubação realizada, seguindo recomendações técnicas para a cultura 4 .

\section{CARACTERÍSTICAS AVALIADAS}

Aos 30 dias do mês de maio do ano de 2013, as seguintes variáveis foram analisadas: altura da Planta
(AP), em m, com auxílio de uma trena, do coleto até o ápice do ramo principal; Diâmetro do Caule (DC), em $\mathrm{mm}$, com auxílio de um paquímetro digital, no coleto; Diâmetro da Copa (DCOP), em m, com auxílio de uma trena, entre as duas extremidades laterais da planta; Área foliar segundo ${ }^{12}$, Número de Ramos Totais (NRT) pela contagem do número total de ramos a partir do coleto e produtividade (g planta ${ }^{-1}$ e kg ha ${ }^{-1}$ ).

\section{PROCEDIMENTOS ESTATÍSTICOS}

O experimento foi montado, seguindo o delineamento em blocos casualizados com três tratamentos e seis repetições. Os dados obtidos submeteram-se à análise de variância e teste de Newman-Keuls para comparação entre médias. Todas as análises foram realizadas utilizando o software SISVAR 5.3 13.

\section{Resultados}

As variáveis relacionadas com o crescimento e produção são mostradas nas Tabelas 1 e 2 . A altura de planta, diâmetro do caule e diâmetro de copa apresentaram-se bastante semelhantes nas plantas, independente do espaçamento utilizado no cultivo. Estas variáveis não diferiram estatisticamente ao nível de $5 \%$ de probabilidade. O número de ramos, área foliar e produtividade apresentaram significativa diferença entre as plantas tratadas. O número de ramos foi, em média, $19 \%$ maior nas plantas cultivadas no espaçamento de 3 x $2 \mathrm{~m}$ em relação as plantas no espaçamento $3 \times 3 \mathrm{~m}$. Quando a comparação é feita com o espaçamento $3 \times 1$ $\mathrm{m}$, o número de ramos foi, em média, $40 \%$ superior nas plantas cultivadas no espaçamento $3 \times 2 \mathrm{~m}$. De maneira geral, a área foliar foi maior nas plantas cultivadas nos

Tabela 1. Caracteres produtivos: Altura de planta, número de ramos e diâmetro do caule de plantas de pinhão manso cultivadas em diferentes espaçamentos.

\begin{tabular}{|c|c|c|c|}
\hline \multirow{2}{*}{ Espaçamentos } & \multicolumn{3}{|c|}{ Variáveis analisadas } \\
\cline { 2 - 4 } & Altura (m) & $\mathbf{N}^{\mathbf{0}}$ de ramos & Diâmetro do caule (mm) \\
\hline $1 \times 3$ & $2,43 \pm 0,1 \mathrm{~A}$ & $5,83 \pm 1,0 \mathrm{~B}$ & $89,7 \pm 4,2 \mathrm{~A}$ \\
\hline $2 \times 3$ & $2,15 \pm 0,1 \mathrm{~A}$ & $9,72 \pm 1,0 \mathrm{~A}$ & $103,1 \pm 6,9 \mathrm{~A}$ \\
\hline $3 \times 3$ & $2,39 \pm 0,1 \mathrm{~A}$ & $7,90 \pm 0,8 \mathrm{AB}$ & $98,6 \pm 4,2 \mathrm{~A}$ \\
\hline
\end{tabular}

Valores representam a média \pm erro-padrão $(\mathrm{n}=6)$. Médias seguidas por uma mesma letra dentro de cada linha não diferem entre si, a $5 \%$ de probabilidade, pelo teste de Newman-Keuls. 
Tabela 2. Caracteres produtivos: Área foliar, diâmetro de copa e produção por planta e produtividade de plantas de pinhão manso cultivadas em diferentes espaçamentos.

\begin{tabular}{|c|c|c|c|c|}
\hline \multirow{2}{*}{ Espaçamentos } & \multicolumn{4}{|c|}{ Variáveis analisadas } \\
\cline { 2 - 5 } & Área foliar (cm2) & Diâmetro de copa (m) & Produção por planta (g) & Produtividade Kg ha-1 \\
\hline $3 \times 1$ & $193 \pm 12,3^{\mathrm{B}}$ & $2,0 \pm 0,1^{\mathrm{A}}$ & $90 \pm 6,8^{\mathrm{C}}$ & $301,7 \pm 15,7^{\mathrm{C}}$ \\
\hline $3 \times 2$ & $162 \pm 12,7^{\mathrm{B}}$ & $1,8 \pm 0,2^{\mathrm{A}}$ & $206 \pm 13^{\mathrm{B}}$ & $342,6 \pm 20,2^{\mathrm{B}}$ \\
\hline $3 \times 3$ & $243 \pm 14,3^{\mathrm{A}}$ & $1,9 \pm 0,1^{\mathrm{A}}$ & $368 \pm 21^{\mathrm{A}}$ & $408,7 \pm 21,5^{\mathrm{A}}$ \\
\hline
\end{tabular}

Valores representam a média \pm erro-padrão $(\mathrm{n}=6)$. Médias seguidas por uma mesma letra dentro de cada linha não diferem entre si, a $5 \%$ de probabilidade, pelo teste de Newman-Keuls.

maiores espaçamentos, ou seja, com menor densidade de plantas. A área foliar foi, em média, $21 \%$ maior nas plantas sob espaçamento de $3 \times 3 \mathrm{~m}$ em relação às plantas cultivadas em espaçamento de $3 \times 1 \mathrm{~m}$. A mesma variável foi, em média, $34 \%$ maior nas plantas cultivadas em espaçamento de $3 \times 3 \mathrm{~m}$ em relação às plantas sob espaçamento de $3 \times 2 \mathrm{~m}$. A produção por planta foi maior nas plantas cultivadas em maiores espaçamentos e menor densidade de plantas. A produção por planta foi, em média, $75 \%$ superior nas plantas cultivadas no espaçamento de $3 \times 3 \mathrm{~m}$ em relação às plantas em espaçamento de $3 \times 1$ m. A mesma variável foi, em média, $44 \%$ superior nas plantas sob espaçamento de $3 \times 3$ em relação às plantas de $3 \times 2 \mathrm{~m}$. A produtividade em $\mathrm{kg} \mathrm{ha}^{-1}$ foi, em média, $26 \%$ superior nas plantas cultivadas no espaçamento de $3 \times 3$ $\mathrm{m}$ em relação às plantas em espaçamento de $3 \times 1 \mathrm{~m}$. A mesma variável foi, em média, $16 \%$ superior nas plantas sob espaçamento de $3 \times 3$ em relação às plantas de $3 \times 2 \mathrm{~m}$.

\section{Discussão}

Por se tratar de uma cultura perene, o clímax produtivo do pinhão manso demanda tempo, devido ao longo período para estabilizar a produção (quatro anos). As diferenças de produtividade registradas no presente trabalho, possivelmente, serão realçadas ao longo dos anos até a produtividade ser estabilizada. Como um todo, os resultados demonstram que o cultivo do pinhão manso em maior espaçamento e, portanto, menor densidade de plantas apresenta maior produtividade.

Independentemente do espaçamento utilizado, as plantas de pinhão manso apresentaram semelhança na altura de planta, diâmetro de caule e diâmetro de copa. O elevado potencial de extração de água e nutrientes do solo por planta de pinhão manso, possivelmente, permitiu exploração de elevado volume de solo necessário para manutenção do vigoroso crescimento vegetativo da espécie, e percepção de pequena diferença entre os tratamentos. O pinhão manso é uma planta xerófila, sobrevive com pluviosidade de $600 \mathrm{~mm}$ anuais, adapta-se a diversas condições de clima e solo ${ }^{14,15}$. O caule suculento atua em condição de déficit hídrico como tampão hídrico ${ }^{6}$. Em adição, o rápido crescimento vegetativo das plantas de pinhão manso aliado ao adensamento, proporcionou ligeiro sombreamento das folhas baixeiras nas plantas cultivadas nos espaçamentos de $3 \times 1 \mathrm{~m}$ e $3 \times 2 \mathrm{~m}$, reduzindo assim, a disponibilidade de energia luminosa. Plantas desenvolvidas sob diferentes níveis de luminosidade apresentam variações fisiológicas em diversos caracteres produtivos ${ }^{16}$. A energia luminosa é desencadeadora do processo fotossintético e interfere consideravelmente no acúmulo de biomassa. Plantas desenvolvidas em condição de baixa itensidade luminosa apresentam reduzido acúmulo massa seca e produtividade $^{16}$.

A competição por água, luz e nutrientes entre plantas de pinhão manso não foi suficiente para interferir no crescimento vegetativo da espécie. No entanto, com o desenvolvimento de mais um dreno, em especial, o mais forte da planta, os frutos, a competição por recursos abióticos, nas plantas mais adensadas, contribuiu para redução da produção por planta e produtividade como um todo.

Em geral, as plantas desenvolvem "folhas de sol" e "de sombra", quando aclimatadas a diferentes níveis de luminosidade. Área foliar específica e unitária; espessura da cutícula; densidade estomática; cloroplastos com menos ou mais grana; menos ou mais tilacoides por 
granum e taxa de assimilação líquida de carbono são algumas das características que variam em resposta à irradiância ${ }^{17}$. A redução da disponibilidade de energia luminosa pode ter contribuído para menor taxa de assimilação de carbono em folhas de plantas de pinhão manso sombreadas, comprometendo a produção de assimilados e produção de frutos. A elevada variação na produção por planta é indício de que as plantas cultivadas em menores espaçamentos e, portanto, submetidas ao intenso sombreamento, apresentaram menor produção por planta e consequentemente menor produtividade em função da reduzida disponibilidade de assimilados oriundos da fotossíntese, bem como pela maior competição por água e nutrientes.

Estudos posteriores, com exploração do pinhão manso em diversos outros espaçamentos, são necessários para determinar a adequada densidade de plantas a ser recomendada. A competição por água e nutrientes aliada ao sombreamento proporcionado pelo elevado adensamentos, limita a produtividade de plantas de pinhão manso.

\section{Conclusões}

A competição por água, nutrientes e luz pouco interfere no crescimento vegetativo de plantas de pinhão manso sob espaçamentos de $3 \times 1,3 \times 2$ e $3 \times 3$ m, no entanto, o sombreamento das plantas aliado à competição por água e nutrientes interfere significativamente na produtividade de sementes da espécie.

\section{Agradecimentos}

Os autores agradecem à Universidade Estadual de Goiás (UEG) pelo apoio financeiro dispensado para condução deste trabalho e à FAPEG, pela concessão da bolsa de iniciação científica.

\section{Referências}

1. Dias, L.A.S.; Muller, M.; Freire, E. Potencial do uso de oleaginosas arbóreas em sistemas silvipastoris. In: Fernandes, E.M.; Paciullo, D.S.C.; Castro, C.R.T., Muller, M.D.; Arcuri, P.B.; Carneiro, J.C. (Org.) Sistemas agrossilvipastoris na América do Sul: desafios e potencialidades. Juiz de Fora: Embrapa Gado de Leite, 2008, 1, 283.

2. Matos, F.S.; Oliveira, L.R.; Freitas, R.G.; Evaristo, A.B.; Missio, R.F. \& Cano, M.A.O. Physiological characterization of leaf senescence of Jatropha curcas L. populations. Biomass and Bioenerg. 2012, 45, 57.

3. Agência Nacional do Petróleo, Gás Natural e Biocombustível (ANP). Disponível em: $<$ http://www.anp.gov.br/id=472> Acesso em: 20 de março de 2012.

4. Dias, L.A.S.; Leme, L.P.; Laviota, B.G.; Pallini, A.; Pereira, O.L.; Carvalho, M.; Manfio, C.E.; Santos, A.S.; Souza, L.C.A.; Oliveira, T.S.; Dias, D.C.F.S. Cultivo de pinhão-manso (Pinhão manso L.) para produção de óleo combustível. Viçosa: LAS Dias, 2007, $1,40$.

5. Tominaga, N.; Kakida, J.; Yasuda, E. K.; Sousa, L.A.S.; Resende, P.L.; Silva, N.D. Cultivo do pinhão-manso para produção de biodiesel. Viçosa: Centro de Produções Técnicas, 2007, 1, 220.

6. Maes, W. H.; Trabucco, A.; Achten, W. M. J.; Muys, B. Climatic growing conditions of Jatropha curcas L. Biomass and bioenerg. 2009, 33, 1481.

7. Fairless, D. Biofuel: the little shrub that coulddmaybe. Nature, 2007, 449, 652 .

8. Achten,W.M.J.; Verchot, L.; Franken, Y.J.; Mathijs, E.; Singh, V.P.; Aaerts, R.; Muys, B. Jatropha bio-diesel production and use. Biomass and Bioenerg. 2008, 32, 1063.

9. Aandréo-Souza, Y.; Pereira, A. L.;Silva, F. F. S.; Ribeiro-Reis, R. C.; Efeito da salinidade na germinação de sementes e no crescimento inicial de mudas de pinhão-manso. Rev. Bras. Sem. 2010, 32, 83 .

10. Souza, A.C.; Ribeiro, R.P.; Jacinto, J.T.D.; Cintra, A.D.; Amaral, R.S.; Santos, A.C.; Matos, F.S. Consórcio de pinhão manso e feijoeiro: alternativa para agricultura familiar, Rev. Agrarian. 2013, 6, 36.

11. Silva, A.T.V.C. et al. Avaliação da senescência foliar de plantas de Jatropha curcas 1 . Submetidas a doses de benzilaminopurina. Rev. Agrotec. 2012, 3, 1.

12. Severino, L. S.; Vale, L.S.; Beltrão, N.E.M. A simple method for measurement of Jatropha curcas leaf area. Rev. Bras. Oleag. Fibr. 2007, 11, 9 .

13. Ferreira, D.F. Sisvar: a computer statistical analysis system. Ciên. e Agrotec. 2011, 35, 1039.

14. Severino, L.S. Viagem à Índia para prospecção de tecnologias sobre mamona e pinhão manso. Campina Grande: Embrapa do algodão. Documento. 2006, 153, 56.

15. Pompelli, M. F.; Luís, R. B.; Vitorino, Hermerson. S.; Gonçalves, E. R.; Rolim, E. V.; Santos, M. G.; Cortez, J. S. A.; Ferreira, V. M.; Lemos, E. E.; Endres, L. Photosynthesis, photoprotection and antioxidant activity of purging nut under drought deficit and recovery. Biomass and bioenerg. 2010, 4, 1207.

16. Matos, F.S.; Gamboa, I.; Ribeiro, R.P.; Mayer, M.L.; Neves, T, G.; Leonardo, B. R. L.; Souza, A, C. Influência da intensidade luminosa no desenvolvimento de mudas de Jatropha curcas L. Rev. Agrarian. 2011, 4, 265. 
17. Brant, R. S.; Pinto, J. E. B. P.; Rosal, L. F.; Castro, E. M.; Oliveira, C.; Albuquerque, C. J. B. Características fisiológicas e anatômicas de Melissa officinalis cultivadas sob diferentes condições de luminosidade. Magistra. 2010, 22, 146.

\section{Marcus V. P. Cassiano, Luis F. O. Borges, Alainy C. S. Nascente, Pollykennya K. F. Alves, Victor P. Godoi, Larissa P. Borges, Mariana S. Carmo, Fábio S. Matos ${ }^{*}$}

Universidade Estadual de Goiás (UEG), Rodovia: GO 330, km 241, Anel Viário s/n, Ipameri-GO, CEP: 75780-000.

* e-mail: fabio.agronomia@hotmail.com 